\title{
Conflicts Intervention and Peace-Building Mechanisms in the West Africa Sub-Region
}

\author{
Andrew Osehi, Enaifoghe \\ University of Zululand, KwaDlangezwa, KwaZulu-Natal, South Africa \\ andyransey@gmail.com
}

\begin{abstract}
Conflict prevail when there is the absence of peace. African countries probably get the worst representation globally with the exception of Syria when it comes to conflicts and violence in the continent. Seemingly, every story emanating from the continent project one atrocity or another. Despite the shouldering of the larger share of the world's conflict, Africa has relatively become more peaceful as well, however in Nigeria, the Boko Haram insurgence in the north is another epicentre. This paper centres on the intervention besides collaborative determination of ECOWAS - AU in mediating peace, and the peacebuilding mechanisms in resolving states conflicts, and to strengthen democracy in West Africa, with the case of Côte d'Ivoire. The organizations' efforts in the Ivorian case reflect discourses and the dynamics of the operations of an effective regional organization, and the international community in addressing conflicts. The collaborative theory was embraced to put things inappropriate perception. Findings show that the implementation of the Contrivance and the Protocol on Democracy and Good Governance by ECOWAS were better prepared to meet challenges related to peace and security in the region. This paper concludes and recommends that organisations who mediate peace in any conflict zone must first understand the cause of the conflict, thereafter timely intervene, and take common positions in applying different mechanisms to prevent, manage and resolve conflicts. It is recommended that to prevent violence and human rights abuses in crisis situations, the organisations of ECOWAS and AU, and particularly SADC should improve interventions procedure.
\end{abstract}

Keywords: Democratic regional organizations; conflict prevention; peace-making; peace-building, and security

\section{Introduction}

Conflict prevail when there is the absence of peace, it is a staid deviation and argument that arise between two or more people on something of interest, and may lead to violence. Conflict is regarded as threats to peace and security. Apparently, every story emanating from the continent of Africa seems to project one violence or another. Debatably, African has experienced about half of the world's conflicts, despite being $16 \%$ of the world population. Amazingly this is a slightly larger share of the world's conflicts than in the 1990s chaotic years of post-cold wars. Nevertheless, there are two main important caveats, the absolute number of conflicts in the world has experienced has considerably decreased in the last two decades. Despite the shouldering of the larger share of the world's conflict encumbrance, Africa has relatively become more peaceful as well (Dorrie, 2016). A continent of 55 nation-states, conflicts only cluster in a few specific regions. According to the Uppsala Conflicts Data program in 2014, only about 12 African nations experienced what is categorized as armed conflicts, but in 2015 countries like Burundi, Niger and Chad made it to the list. Geographically, Africa's conflicts are tightly clustered along an arc stretching from northern Mali through southern Algeria, Libya into Egypt, extending into the Sinai Peninsula (Dorrie, 2016).

In Nigeria, the Boko Haram insurgency ravaging in the northern part of the country is another epicentre interestingly it is considered the deadliest conflicts on the continent of Africa which cannot be categorized as terrorist conflict, though it is gradually spreading into other African neighbouring states (Dorrie, 2016). It is positioned in relative proximity to an area of a hot spot in the centre African Republic, the eastern DRC, South Sudan, Darfur and Burundi, regions. On the eastern coast of Africa, we have Somali civil war which is currently ongoing strong after three decades. Basically all African modern conflicts are thus exceedingly confined and interestingly they flout unsophisticated elucidations based on stereotypes (Curtis, 2012). Therefore, there is the need for the institution of the Economic Community of West Africa States(ECOWAS) to collaborate with African Union (AU) to devise a strategy to intervene and resolve the various conflicts within its region. In 2002 the then Organisation of African Unity (OAU) transition to African Union(AU), adopted several mechanisms and protocols defined AU's position and role in peacekeeping and peace-making, as well as its commitments to strengthen democracy and good governance in Africa. This marked shift policies and practices of the then OAU. It is principally because the OAU Charter highlighted commitments by members to maintain peace and security on the continent, the principle to respect sovereignty and territorial integrity of member states and its non- 
interventionist stance during periods of conflict in several African countries elicited concerns over the relevance of the $\mathrm{OAU}$ in upholding and stimulating peace and security within the region.

The failure of the OAU to intervene decisively in the Rwandan genocide and conflicts in Liberia, Sierra Leone, Somalia and the Democratic Republic of the Congo (DRC), revealed its inability or unwillingness to take action to resolve conflicts even if gross violations of human rights and atrocities were committed. The Constitutive Act of the AU in 2002 rejects unconstitutional changes of government and the new organisation of AU developed mechanisms and protocols to promote democracy and good governance. The African Union established the Peace and Security Council (PSC) in 2004, with its provision to recommend that the Assembly of heads of state for the Union to intervene in states experiencing crimes against humanity, this highlights a major change in way conflict resolution is viewed under the African Union (Kode, 2016). The principle of rejecting unconstitutional changes of government has been significantly strengthened and given legal backing by the $\mathrm{AU}$ organisation, and in practice the AU organisation has intervened in countries where changes in government have been unconstitutional, and where peace and security have been threatened. In the case of ECOWAS, its intervention in Liberia and Sierra Leone conflicts, and the need to strengthen its peace and security mechanisms necessitated the advance of the Protocol involving the Instrument or Mechanism for the Prevention of Conflict, Management, Resolution, Peace and Security (1999), the Protocol on Democracy and Good Governance (2001) (Kibasomba, 2002). These protocols were aimed at enabling a better-coordinated retort to conflict and crises in the region.

The AU organisation alongside the ECOWAS intervention role played in the Ivorian crisis is a good example that increasingly came under analysis. Then again, the peace-production and peacekeeping endeavors of these associations were applauded for averting further barbarities. Their efforts to restore peace were not often respected by various parties involved in the conflict, being criticised in some quarters. Côte d'Ivoire became a test case for rapid interventions by regional actors at a time when the Organisation for African Unity (OAU) and ECOWAS experienced what is called transitional changes in order to upgrade so as to meet what it requires to ensure peace and security in Africa in the 21st century (David, 2016). The specific obligations, structure, economic capability and the degree of sustainability of regional determinations to ensure that conflicts are resolved, principally with regards to peace-making, peace-keeping, and peace-building came under questioning. Discussions additionally centred around the near preferred standpoint of provincial and UNauthorized mediations, the inability to react to violations against humankind and destruction in Rwanda, the manageability of African-led peacekeeping activities and the criticalness in the operationalization of some UNled tasks. The mediations of AU in Burundi in 2003 and Somalia in 2007, the ECOWAS drove activity in Liberia in 1990, and Sierra Leone in 1997, expanded desires concerning the crucial part of African-drove peacekeeping missions (Shillinger, 2009). This study basically presents the peace-keeping role of the ECOWAS, the AU and the international community in the resolution of conflicts through collaborative efforts, and highlights the dynamics involved in the takeover of regional peacekeeping missions by UN operations.

\section{Literature Review}

A Cursory Review on African States' Conflicts and Insurgencies: In Nigeria, the frequent reports on Boko Haram throughout 2015 came with hopes. Though the uprising is said to be one of the deadliest conflicts that Africa has now firmly spread into other neighbouring states as well, it has recorded the lowest levels of deaths according to report as predicted in 2015 forecast (Dorrie, 2016). The president of Nigeria Mohammad Buhari finalized some specific modification son how conflicts are managed, these seem to be paying off on the long run as the Nigerian military continue to record victory over the sets group (Boko Haram which literally means 'western education is evil'). The current military successes in combatting the set groups labelled as the Boko Haram are depended on spending billions on modern military gear that none of the neighbouring countries involved can actually afford, riding all of them into serious debt. France and the United States provide Nigeria with critical assistance, both in terms of intelligence and combatting other terrorist groups farther north, so that Nigeria's army can therefore focus on the Boko Haram threat. This goes without saying that it is not terribly sustainable. Nevertheless, it is argued that the Boko Haram insurgency has continued to be a substantial source of violence in both in Chad, Niger, Cameroon, and Nigeria, though not on the extremist level as experienced in 2014 and early 2015 which marked the peak of the violence (Dorrie, 2016). 
In African today, the Mali-Algeria-Libya triangular conflicts are regarded as the international terrorist hot spot. There are several conflicting groups which include the Al-Qaeda in the Islamic Maghreb is the most active group across some of the most arbitrary borders in the world, these conflicts are interrelated. Their firmness will still require primarily national approaches (Peter, 2016). According to Dorrie (2016), Mali is only currently held unruffled by the existence of the international troops and donors it receives, while still becoming more insecure even in the country's south. It is quite unfortunate that the corrupt and inept political elite obviously has learned nothing from the near collapse experienced in the year 2012, and there is only little hope that it will do so miraculously in the near future years ahead. As the global community is too capitalised to let Mali crash, however the people will nevertheless witness what is called widespread insecurity and belligerent in the northern part of the state, while on the other hand the south will experience more terrorist spasms targeted to the government, with it establishments linked with West. In Algeria however, there is indeed a fascinating circumstance, the political administrations are so elite-driven, securely entwined with the security institution, that they are fundamentally impassable from the external.

President Abdelaziz Bouteflika amalgamated supremacy over the last few years, but unfortunately he is an old man with a dyed-in-the-wool history of serious illness. Algeria's internal power balance is heavily grounded or built on using funds spawned by the state's rich benefaction with hydrocarbons to buy modern and innovative kits for its bloated military apparatus, thus charge officers and recruited men happy, in order to suppress public disgruntlement. The oil prices in a slump and internal conflicts over Bouteflika's succession, the worst-case scenario would see anger over low living standards and lack of opportunity boil over, mix with elite factionalism. In the Central Africa Republic up to 2013, the conflicts in the Central Africa Republic (CAR), and South Sudan linger to flame off over the period of 2016 till present. These states have gotten to delicate postconflict concessions in the form of a political election in the CAR and the administration of the national unity in South Sudan. It is imperative to note that in both nations, the central government had a very limited power or authority even before the civil wars besmirched their capabilities to basically nothing to write home about. It is therefore predicted that there will continue to exist low-level violence as well, with flare-ups likely in case the UN peacekeeping operation with MONUSCO decides to bring the hammer down on some of these groups.

According to Dorrie (2016), there were some scandals involving UN peace-keepers sexually abusing children in 2015 (Dorrie, 2016). In Somali, the catastrophes of Somalia continue to be in Darfur in Sudan, Darfur is proficient in an uptick in belligerent lately and there is no motive, certainly not the non-exiting international attention. And of course in Burundi, much was set to be contingent on the pronouncements of the African Union, with nearly every probable form of interference apprehensive with hesitations. A very noteworthy development would be the distribution of military dynamism against the will of the organisation under section 4(h) of the union's constitutive act (Curtis, 2012). According to a World Bank report, it warns that South Africa is another country to watch out for with her current attacks on foreign nationals by its citizens. South Africa remains the second largest economy after Nigeria in the south of the Sahara, and will absolutely not decentralize into large-scale core clash, there are few perturbing signs of progress however, the country's economy had recently fallen into junk status, and it keeps going dejected the ditch, former President Jacob Zuma of South Africa appeared to be more incompetent or rather inept by the day while racial tension continues to run high in the country over a decade after end of apartheid. It is on record that South Africa remains the highest level of inequality in the world according to World Bank (2016) report, more than two decades after apartheid.

There continue to be communal turmoil with considerable loss of life in 2015 and 2016, along with the line of the Marikana killings in 2016, the systematic prevalent of xenophobia and intolerance in the country, which may likely see the South African people turning contrary to each other as an alternative of the current state. However, the conflict that surrounded Côte d'Ivoire in 2002 divided the whole country for eight years, with its south part run by the Government and the north part controlled by the rebel forces. The violence and divisions in the country caused the reversal of major economic returns that had been gained since independence, and the political uncertainties threatened regional stability. While Côte d'Ivoire's economy blossomed after independence, acknowledgements in part to readily available labour from nationals who had migrated from neighbouring countries in West Africa, signs of political tensions became apparent in the 1990s and culminated with a coup d'état in 1999, a disputed election in 2000 and an attempted coup in 2002 (Dorrie, 2016). Between 2002 and 2010, Côte d'Ivoire experienced ethnic-related tensions, with the rebels running a parallel 
government. Elections were postponed repeatedly despite diplomatic interventions by the Economic Community of West African States (ECOWAS). The African Union (AU) and France, and military intervention by the United Nations. Even after elections were finally held in 2010, disputes around the electoral results led to violence and human rights violations and brought the country to the brink of another brutal civil war. The difficulties faced by the belligerents in agreeing on a way forward at the different stages of the conflict meant regional actors and the international community had to step in on a regular basis to prevent further escalations of violence during periods of relative peace (Dorrie, 2016).

\section{Material and Method}

A documentary analysis or method was adopted in this study as it helps to enlighten researchers and thereby make sense of written documents, which exist either in the unrestricted or private purview (Mogalakwe, 2006). This suggests that researchers can select the relevance of the documents they access on the basis of their applicability to the study. In that same vein another researcher argued that "in the documentary analysis, the criteria for selecting documents, or for focusing on particular extracts, should reflect the issues on which evidence is pursued" (Dey, 2005: 105). This study adopts the collaborative theory or approaches to resolving conflict in order to put things inappropriate perception.

Theory: Collaborative Theory to Conflict Intervention: The collaborative theory to resolving conflict basically provides an introduction to a variety of conflict management techniques, incorporating a combination of theory and practice, and geared towards a broad audience (Isenhart and Spangle, 2000). In collaborating method, it strives to ensure that two aggrieved sides are satisfied. It requires an open discourse of the considerable number of issues and concerns, investigation of elective arrangements, genuineness and responsibility from every one of the group. To be fruitful, the collaborating method of intervention members should have the capacity to surface worries in a non-undermining way and think inventively. It is imperative to first comprehend the distinction between a bargaining method and a teaming up style: bargaining is 'horseexchanging', surrendering things you need in the expectations that the opposite side will do likewise and that you can live with the result. In a coordinated effort, the two sides are endeavouring to find an answer which genuinely fulfils the necessities of each (Isenhart and Spangle, 2000). The teaming up style is a fantastic method to combine bits of knowledge from individuals with alternate points of view on an issue, and the outcome can be a solid responsibility for the arrangement from each side. The drawback of the teaming up style is that it is difficult to do! It requires close consideration regarding the current issues (concerns, not simply positions) and to the enthusiastic condition of the opposite side.

\section{The Interventions Mechanism in Conflict Situations in Africa}

In the 1990s the implementation of majority rule system reforms or changes and organized multiparty system election was implemented by most African nations, which flagged a move far from one-party governmental issues and the multiplication of military administrations that had described Africa's nation in the prompt postautonomy period. There was a chance for common society and autonomous media to beware of government abundances and consider public authorities to be responsible and accountable for their stewardship as they exercise the people's mandate. In this light elections turned into a normal component in African governmental issues and a few nations corrected their constitutions by including arrangements to regard the control of law and advance great administration (Dorrie, 2016). This implied a new beginning for most African nations, particularly when contrasted with the quick post-freedom period, when administering parties caught control and forced serious limitations on the political restriction and common society. Nonetheless, this period likewise saw frightful and crushing clashes in nations like Burundi, the DRC, Liberia, Rwanda, Sierra Leone, Somalia and Sudan. While each one of these contentions was intra-express, all had genuine ramifications for their separate locales, and some really spread past national outskirts. While belligerents battled and conferred net infringement of human rights-murdering, lynching and snatching civilians - there was a call to mediate and put an end to these abominations by the international community (Swart and Solomon, 2004).

According to Klingebiel (2005), there were instances, where several questions were raised about the inability or the reluctance of the international community to put an end to the atrocities with the abuse of human rights in some of these conflict states particularly the African organisations. At the end of the Cold War, there have 
been banters about the parts and duties, the planning and the yearnings of the international community especially, the UN, previous pioneer powers and regional actors, in interceding in strife influenced territories. In putting forth a defense for outsider mediations in conflicts circumstances, Zartman (2005:1) contends that foreign performers can't 'take cover behind the dread of their own losses or of long-haul association as a reason for inaction'. The test for an international organisation in interceding in clashes lies in quickly assembling suitable powers to uphold peace and consolidating such military activities with discretionary arrangements between warring groups.

In situations where clashes eject and there is a gross infringement of human rights and barbarities conferred by those associated with the contention, there have been worries about the timeframe it takes to approve and set up together peacekeeping powers and send them to the warring states to keep up the peace and secure existences of the general population. Regardless of the solid case for why international community ought to mediate in specific clashes, Mays (2002) advises us that 'the authorizing of peacekeeping activities and intercessions in clashes or the growing of continuous tasks relies upon the endorsement of all UN Security Council individuals'. Furthermore, there are worries that the perpetual individuals from the Security Council have settled on choices about where and when to intercede depending, not on the need to ensure people or authorize a peace understanding, however on the vital connections they have with nations influenced by struggle (Adebajo, 2011). It can likewise be contended that the absence of firm activity by the Council in specific clashes radiates from the absence of specific financial, political or vital interests individual members from the Council have with nations in strife or their pre-occupation with different emergencies. The annihilation in Rwanda, for instance, and the withdrawal of the United Nations Assistance Mission in Rwanda (UNAMIR) exhibits the connection among countries and individuals from the Security Council and the desires of the last in mediating in specific clashes over others (May 2002). The way that most individuals from the Council did not have major vital interests in Rwanda at the time, especially in the post-Cold Wartime, the intersection of contentions that required the consideration of the global network amid that period and the encounters of the United States in Somalia prevented individuals from the Council from completely submitting.

The Organisational Transformation from the OAU to AU (African Union): It has been noted on several occasions the United Nations Security Council has infrequently responded adequately to conflicts, and on time in Africa, even though most of the deliberations on peace and security matters concern African countries (Adebajo, 2011). There comes a noteworthy thought, if the international organisation as the United Nations (UN) neglected to intercede in specific clashes, what could territorial organisations like the AU do to avert mass monstrosities when clashes emitted in Africa? In the result of the Rwandan decimation and different clashes around Africa, the then OAU (the Organization of African Unity) was frequently reprimanded for neglecting to assume the liability to mediate in clashes, authorize peace and stop human rights infringement. While the OAU had an instrument to review strife and savagery, as the Commission on Mediation, Conciliation and Arbitration, its endeavors to determine African clashes rather adopted a political strategy, underscoring the utilization of peacefulness and regard or respect for the sway and regional respectability of its member states (Foltz, 1991; Ajulu, 2004; Yound, 1991). In this respects, specially appointed boards of trustees were set up by the Commission additionally to address savagery and struggle, however as Deng contends, most African pioneers and leaders had framed agreeable partnerships with each other, and this implied, during strife, individuals from these councils were more keen on ensuring the security and assurance of their associates than settling the main problem of contentions. In spite of the foundation of the Commission on Mediation, Conciliation and Arbitration, the then OAU amid its reality favored non-obstruction in the inward undertakings of its states amid the contention, and was viewed as 'a quiet spectator to monstrosities submitted in various member states' (Gomes, 2008: 113- 30).

Apparently, the leaders of African states met in Sirte, Libya in September 1999, to survey and review the OAU Charter in order increase the productivity level, boost efficiency and adequacy of the mainland alliance to address the difficulties witnessed by the continent. One of these difficulties was the scourge of contention and the consequences for the general population of Africa. The Sirte Declaration consequently required the end of contention and conflicts, keeping in mind the end goal to accomplish this and different targets, they chose to shape the new association known as the African Union (AU). This was trailed by the foundation of the AU in 2002 , the point of which was to advance peace, security and dependability, popularity based standards and organizations, standard cooperation and great administration, and to strengthen democracy in Africa 
particularly. Aware of the exercises from the then OAU in the territory of peace and security, strife avoidance and goals, the new organisation is known as the AU therefore received a more interventionist approach through its systems, structures and foundations (Besada, Goetz and Werner, 2010; Khadiagala, 2012). Be that as it may, in 2004, the AU thought of another technique and built up its Peace Security Council (PSC) through the Protocol identifying with the Peace and Security Council (2002). The board made out of 15 individuals, the PSC was made to oversee and resolve strife and conflicts, which has a command to lead peace-production and peacekeeping on the mainland of Africa. Article 7 (e) on the Protocol connecting to the foundation of the PSC engages the PSC to prescribe to the Assembly mediation for the benefit of the AU in nations experiencing atrocities, massacre and wrongdoings against mankind (AU, 2002).

The way and manner that the OAU's instrument for strife and conflicts aversion, administration and goals (1993) was supplanted by the AU's PSC feature the adjustment in mentality and arrangements from nonobstruction to non-impassion. Mwanasali (2008:41) states that this change from non-obstruction to non-lack of concern 'flags a noteworthy move in African political reasoning and foreshadows or shows the beginning of an interventionist stage in the African continent administration of peace and security'. This move in mentality was clear in the mediation of African-driven peacekeeping powers with a command from the AU in Burundi (2003- 04), Sudan (2004- 06), (Somalia 2007) and Central African Republic (2013). The mediations in these nations have created blended outcomes yet demonstrate a noteworthy move in the approach of the AU, despite the fact that the AU states unmistakably that it regards the privilege to power and regional trustworthiness of its individuals. In the instances of the Central African Republic and Sudan, the AU understood the material and money related expenses of peacekeeping missions and this exhibited the requirement for help from the universal network.

Regardless of its adjustment in the state of mind to endeavors went for mediating in struggle circumstances to bring peace, and the blended victories following its intercessions in Burundi, Côte d'Ivoire and Sudan, the AU has wound up in a circumstance much the same as that of its forerunner. This is especially valid on account of Burundi, which was dove into the struggle in April 2015 after a choice by President Pierre Nkurunziza to remain for a third term in office, which brought about resistance from political gatherings, common society and local nationals (David, 2016). The AU organisation voted not to send troops to Burundi regardless of the way that about 1,000 Burundians had been killed following a very long time of brutal dissents, an endeavored rebellion in May 2015, an undeniably critical compassionate circumstance and worries that Burundi could totally implode at the time the AU settled on its choice (Kode, 2016). In West Africa, the force and complexities of contentions in the 1990s-especially in Liberia (1989- 97 and 1999-2003), Sierra Leone (1991-2002) and Guinea-Bissau (1998- 99) - called for earnest intercessions to stop mass outrages, killings, demolition of property and state organizations, and the aggregate fall of society. The idea of the brutality had local ramifications with monstrous streams of displaced people crosswise over fringes which undermined the dependability of the district. The mediation of ECOWAS in Liberia and Sierra Leone helped stop the killings and the wanton demolition of the property. Military mediation, especially in Liberia, Sierra Leone and later in Côte d'Ivoire, was gone before by, went with or took after conciliatory endeavors that prompted the consenting to of peace arrangements like the Cotonou, Abuja and Accra Peace Agreements on account of Liberia and the Lomé Agreement on account of Sierra Leone (Kode, 2016).

The accomplishments made after intercessions in Liberia (1990) and Sierra Leone (1997) constrained West African pioneers to take a gander at more organized and compelling approaches to drive local peacekeeping and peace-production endeavours. In such a manner, the various leaders of the local body consented to build up structures and instruments to encourage a more powerful and effective intends to intercede in future clashes and conflicts. ECOWAS set up an instrument for strife aversion and prevention, administration and goals, peacekeeping and security, in 1999 to control the association in counteracting, overseeing, settling interstate and intrastate clash and keep up peace and steadiness. The component had structures including the Council of Elders (Council of the Wise), the Mediation and Security Council and the Defence and Security Commission to address security issues (Kode, 2016). This component was additionally formed into the Supplementary Protocol on Democracy and Good Governance in 2001. The Protocol was intended to fortify majority rules system of democracy in the locale with the thought that the nonappearance of genuine vote based systems and energetic organizations were at the focal point of contentions in the district. The formalization of a reserve drive called for under the 1999 Protocol would have suggestions for the continent 
and for the AU's peacekeeping mission's endeavours. The choice by the AU's Peace and Security Council to build up an African Standby Force implies ECOWAS is the most developed in the formation of its provincial power.

Peace Mediation and Collaborative Role of the ECOWAS and AU in Côte D'ivoire Conflict: The mechanism on Peace Mediation and the Collaborative effort of ECOWAS and AU adopted for the creation of an earlywarning system, the Council of the Wise and the special mediators on conflict and peace to pre-empt watersheds, was set up to react fittingly in nations influenced by strife and conflicts. It speaks to the most comprehensive structure for tending to dangers to peace and security in the locale, as it bolsters endeavours to pre-emptively address potential clash circumstances before they raise and gives ECOWAS duty to add to post-struggle improvement and reproduction (Zounmenou and Loua, 2011). This made exceptional delegates in struggle zones to liaise with local actors and the AU association. In 2001 ECOWAS grasped the Democracy and Good Governance Protocol (DGGP) keeping in mind the end goal to address a portion of the political clashes and administration disappointments that provoked clash in the locale. This convention built up the rules for the association for solid decisions, and along these lines approaches individuals to regard vote based standards and constitutions, and rejects illegal changes of government. Notwithstanding, in 1993 the ECOWAS Treaty was amended, giving supranational status on the organisation, to organize human security trying to reposition it to address the difficulties experienced by West African states toward the end of the Cold War. With the advantage of insight into the past and with encounters accumulated from its intercessions in Liberia and Sierra Leone clashes, ECOWAS member states understood the criticalness of; maintaining a strategic distance from postponements to activate troops from different parts of the world, having a decent comprehension of the geopolitics of the district: and, in this manner; received local way to deal with settle clashes (David, 2016). The local alliance embraced the Protocol Encompassing Mechanism for Conflict Prevention, Management, Resolution, Peacekeeping and Security in 1999 (Ekiyor, 2017). The Protocol on Non-animosity was embraced to deliver dangers identified with the interstate clash and approached ECOWAS individuals to cease from debilitating to utilize the power and abstain from overlooking threats against each other. The Protocol on Mutual Assistance on Defense was clear about the aggregate reaction of all individuals on security issues, as it noticed that dangers to one member influenced security in the whole locale. These conventions were likewise received in the quick post-autonomy period, strife and unlawful changes in government were being supported by neighboring nations.

The intercession endeavors of the ECOWAS association in clashes within the area is in this manner upheld by the Mechanism and Protocol on Good Governance in accordance with arrangements on peace, security, the advancement of human rights and the insurance of nationals set up in the systems of the UN, the AU and the New Partnership for Africa's Development. ECOWAS perceives the centrality of teaming up with the AU and UN in fortifying peace and security in the entire region and in interceding in struggle circumstances. This joint effort is viewed as basic by ECOWAS pioneers and leaders and is commenced on lawful and moral commitments. As far as lawful commitments, it perceives the part of the UN in keeping up peace and security. It is one of eight authoritatively perceived local organisations in Africa and it teams up with the UN and AU in accordance with Chapter VIII of the UN Charter. The systems that guide ECOWAS's mediations in clashes and its commitments in post-struggle remaking which reflects enter standards in the Constitutive Act of the AU and the UN Charter and their rules on peace and security.

The ethical commitments are driven by the obligation to secure (R2P - Responsibility to Protect), especially in acknowledgement of the repercussions of contention inside, viciousness and misuse executed against civilians and the inclination for interior clashes to rise above national limits. Besides, on 31 October 2010, without precedent for around 10 years and after a few delays, Ivorians finally went to the polls to vote. The elections were seen by delegates from the AU and ECOWAS notwithstanding others from universal associations and the European Union (EU). The Independent Electoral Commission (IEC), On 4 November 2010, reported that Gbagbo had gotten $38.04 \%$ of the votes, against $32.07 \%$ for Ouattara and $25.24 \%$ for Henri Konan Bédié (HRW, 2011). This required a run-off by the initial two hopefuls, in accordance with sacred arrangements.

As per Afolabi (2012), the board and its intercession endeavors were eclipsed in a path by the 'varying interests and wanted political results of the individuals in accordance with their different advantages, the presence of an association with President Gbagbo, ideological introduction and the impact of France, Côte d'Ivoire's previous frontier ace. In the wake of debilitating all political and serene endeavours to determine the emergency, French 
and UN powers helped the FN, which had promised dependability to Ouattara and was renamed the Republican Forces. A few exercises can be drawn from the mediation by the AU and ECOWAS in the Ivorian strife. The position taken by a few pioneers of the AU and ECOWAS to advance down and hand over power following the production of the aftereffects of the run-off decisions 2010 exhibited that African pioneers would now be able to reprimand the undemocratic inclinations of their associates, particularly when these companions lose elections and choose to hold tight to control. It was a positive message that the Democracy and Good Governance Protocol received by ECOWAS was by and large effectively connected in Côte d'Ivoire.

Findings and Discussion: Just like in 2002, after the attempted coup, there was a quick response from regional actors. The argument is that the interventions mechanisms adopted did not demonstrate a satisfactory leadership in ECOWAS and the AU collaborative efforts in mediating peace and peace-building in the conflicting states, with the diplomatic engagements with the parties on the conflict. However, this mechanism did not create the right measures to ensure that actions made amid transactions and negotiations were completely authorized or actualized. Despite the fact that few ECOWAS pioneers had demanded that military move was to be made on the off chance that strategy flopped, however at last there were divisions among the leaders, they were not joined to the extent that this position becomes worried because of some close to home interests. Gbagbo had demanded amid the contention that the difficulties experienced by Côte d'Ivoire were caused by 'settler powers' endeavouring to destabilize the nation. This view resounded with his supporters, especially the Young Patriots, who related to his approaches and convictions, regularly bolstered his activities, and had done assaults against French business interests. This view additionally charmed Mbeki to Gbagbo and he selected rather for an arranged arrangement between the warring groups. Moreover, there was an inclination among ECOWAS leaders that Mbeki was pushing for an arranged arrangement between President Gbagbo and Alassane Ouattara as opposed to embracing the position held by a few ECOWAS leaders that Gbagbo must surrender control. Indeed, even strategic endeavours were not extremely fruitful. Mbeki and Odinga, Peace envoys did not prevail with regards to convincing Gbagbo to surrender control as the brutality held on. This along these lines demonstrates the shortcomings in recognizing the correct people to lead strategic commitment by the association. The mediations by ECOWAS and the AU additionally featured divisions in approach positions at both local and mainland levels. Such divisions additionally helped Gbagbo in buying additional time and holding tight to control for longer, consequently delaying the viciousness and the monstrosities conferred. At the territorial level, Nigeria, Burkina Faso, Senegal and Sierra Leone were supportive of firm activities for driving Gbagbo to leave control and, if every strategic exertion flopped, likewise military activity. Others including Guinea, Liberia and to a specific degree Ghana, Togo and Benin did not take clear positions on the issue. The disappointment of the AU and ECOWAS to enough determination the emergency implied that obligation was given over to the UN and France. Without sufficiently tending to the subject of citizenship, it turned out to be progressively troublesome for recognizable proof procedures to be dealt with, which was the principle reason the elections were put off something like six times.

\section{Conclusion and Recommendations}

Conclusively, it was discussed in this paper that the conflict which engulfed Côte d'Ivoire in 2002 apparently divided the country for eight years. Due to violence and divisions in the country the major economic gains that had been made since independence were reversed, and the regional stability was threatened by political uncertainties. While Côte d'Ivoire's economy blossomed after independence, acknowledgements in part to readily available labour from nationals who had migrated from neighbouring countries in West Africa, signs of political tensions became apparent in the 1990s and culminated with a coup d'état in 1999, a disputed election in 2000 and an attempted coup in 2002.

It was also argued that the lack of action by the Council in certain conflicts emanates from the lack of particular economic, political or strategic interests of members of the Council with countries in conflict or their preoccupation with other crises. The genocide in Rwanda, for example, and the withdrawal of the United Nations Assistance Mission in Rwanda (UNAMIR) was cited as a good example, which demonstrates the relationship between nations and members of the Security Council and the aspirations of the latter in intervening in certain conflicts over others. This paper has argued that the ECOWAS adoption of the Mechanism and the Protocol on Democracy and Good Governance, implied that its individuals were aware of what should be better arranged to address difficulties identified with peace and security in the sub-area. It likewise showed that ECOWAS 
individuals trusted that peace and security were important for a majority rule government system to flourish. The instrument on Peace Mediation and the Collaborative exertion of ECOWAS and AU embraced for the making of an early-cautioning framework, the Council of the Wise and unique go-between to pre-empt watersheds, that was set up to react suitably in nations influenced by strife and conflicts was an appreciated improvement.

It was viewed as the most comprehensive structure for tending to threats to peace and security in the district, as it underpins endeavours to pre-emptively address potential clash circumstances before they raise and gives ECOWAS obligation to add to post-struggle improvement and reproduction. At long last, the position taken by the pioneers of the $\mathrm{AU}$ and ECOWAS to venture down and hand over power following the production of the aftereffects of the run-off races 2010 showed that African pioneers would now be able to revile the undemocratic propensities of their grandees, particularly when they lose elections and choose to hold tight to control. It was also a positive message that the Democracy and Good Governance Protocol received by ECOWAS was by and large effectively connected in Côte d'Ivoire. In 2002, after the endeavoured upset, there was a brisk reaction from territorial actors. It was characterized that 'Contention win when there is the nonappearance of peace, since it is a staid deviation and contention resulted between at least two individuals that regularly prompt viciousness'. The struggle is viewed as dangers to peace and security.

\section{Recommendations}

Reject Unconstitutional Changes of Government: In the first phase of the civil war, the conflict and peace intervention strategy of ECOWAS and the AU is commendable. The matter of the fact that several leading African states including Nigeria and Ghana denounced the coup attempt against Gbagbo. It demonstrated that leaders of these African States adhered to key principles backed by protocols which rejected unconstitutional changes of government. This perhaps set a precedent as similar coups in Togo, Mali and Guinea Bissau were denounced by ECOWAS and the AU, with ECOWAS in particular imposing sanctions on these countries and suspending their membership.

Peace Negotiation: Peace Talks should be encouraged at all times and a call to roundtable discussion should be carried out or emphasis that can be credited with addressing the key issues at the centre of the conflict.

Implement Peace Agreements: As a matter of fact ECOWAS confronted many challenges and was unable to fully warrant the implementation of peace agreements. It has successfully averted a full escalation of the conflict on several occasions and made progress in the implementation of certain sensitive aspects of the peace agreements.

Legalize intervention in conflict zones: ECOWAS and the AU successfully resolve conflicts through the legalization of the various protocols, even in the case of Côte d'Ivoire. Under the supervision of ECOWAS and the $\mathrm{AU}$, different parties to the conflict in Côte d'Ivoire signed several peace agreements but most of the agreements could not be implemented as there were no enforcement mechanisms to make the belligerents respect the provisions.

Timely Interventions: The organisations of ECOWAS and the AU leaders played their role in consultations with Gbagbo and the president-elect, Alassane Ouattara to prevent an outright civil war which would have had ethnic connotations. The AU's position in resolving the conflict was closely aligned with that of ECOWAS and the UN, particularly in their public endorsement of Ouattara as president in the aftermath of the run-off and amid the violence that engulfed the country after the 2010 polls.

Reject the Use of Force: Uganda and South Africa were vocal about its rejection of the use of force, is one of the leading nations involved in the mediation efforts, maintained that the option of creating a power-sharing government should be pursued. In the face of Gbagbo's regional and global isolation, the divergent views of individual members of ECOWAS and the AU member states showed that he had support on the continent, which was one of the factors that enabled him to hang on to power for a long time. 
Common positions: In applying the different mechanisms in place to prevent, manage and resolve conflict, members of both ECOWAS and the AU need to ensure that they take common positions in relation to leaders who cling to power through unconstitutional means. This study further concludes with a series of recommendations for the Southern Africa peace-building procedure, aimed at supporting and informing the advancement of South Africa's civilian capacity mechanisms. The key recommendations as lessons for the Southern Africa organisation and South Africa are outlined as below: It is recommended that a wider discussions should be held among policymakers on the roles and functions of South Africa's new development agency, the South African Development Partnership Agency (SADPA); It recommends that South Africa's engagements should be preceded by the development of a longer-term strategy, which should take into consideration current debates and discussions around civilian capacities in mediating peace internationally.

South Africa should use its expertise and experience to complement and enhance the various engagements of multilateral institutions to promote safety and stability. The government, particularly in its diplomatic relations, defence, trade and coordination of actors and institutions - should further refine the country's comprehensive approach to post-conflict peacebuilding and reconstruction. The value of this recommendation is in what it can add to existing knowledge on the impact of civilian capacities in conflict resolution and prevention in South Africa (drawing on the background of the xenophobic attack on fellow but foreign Africans in the Republic), and around the world. Its purpose is to add to the development of SADPA and support South Africa to improve its civilian capacity mechanisms in conflict prevention, peace-building, peace-making and sustain socio-economic development, and peaceful coexistence among people, because South is Africa's window to the world in terms of foreign direct investment.

\section{References}

Adebajo, A. (2011). UN Peacekeeping in Africa: From the Suez Crisis to the Sudan Conflicts (Boulder, CO: Lynne Rienner, 2011).

Afolabi, B. T. (2012). ECOWAS and Conflict Mediation in West Africa', in U. Engel (ed.), New Mediation Practices in African Conflicts (Leipzig: Leipziger Universitätsverlag GmbH, 2012), 169-93.

African Union. (2002). Protocol relating to the establishment of the Peace and Security Council of the African Union. Addis Ababa, African Union.

Ajulu, R. (2004). African Security: Can Regional Organisations Play a Role? in S. Field (ed.), Peace in Africa: Towards a Collaborative Security Regime (Johannesburg: Institute for Global Dialogue, 2004).

Besada, H., Goetz, A. \& Werner, K. (2010). African Solutions to African Problems and Shared R2P', in H. Besada (ed.), Crafting an African Security Architecture: Addressing Regional Peace and Conflict in the 21st Century (Surrey: Ashgate 2010), 1-14.

Curtis, D. (2012). The International Peacebuilding Paradox: Power sharing and Post-Conflict Governance in Burundi", African Affairs, 112, 72-91.

David, K. (2016). The Complexities of Democracy building in the Conflict-Affected States: The Role of ECOWAS and The African Union in Côte D'ivoire.

Dey, I. (2005). Qualitative data analysis. London: Rout ledge, Taylor and Francis Group.

Dorrie, P. (2016). The wars are ravaging Africa in 2016. The National Interest. The Buzz. www.nationalinterest.org

Economic Community of West African States (ECOWAS). (2008). The ECOWAS Conflict Prevention Framework, Regulation MSC/REG.1/01/08, $16 \quad$ January 2008, <http://www.lawschool.cornell.edu/womenandjustice/upload/ECOWAS-Conflict- $\quad$ PreventionFramework.pdf>, accessed 4 November 2017

Ekiyor, T. (2017). ECOWAS Conflict Prevention Framework (ECPF): a new approach to an old challenge', West Africa Civil Society Institute Op-Ed, 1 June 2008, <http:// responsibilitytoprotect.org/ECOWAS\%20ECPF\%20Ekiyor.pdf>, accessed 25 October, 2017.

Foltz, W. J. (1991). The Organisation of African Unity and the Resolution of Africa's Conflicts', in F. M. Deng and I. W. Zartman (eds), Conflict Resolution in Africa (Washington, DC: The Brookings Institute, 1991).

Gomes, S. (2008). The Peace-making Role of the OAU and AU: A Comparative Analysis', in J. Akokpari, A. Ndinga Muvumba and T. Murithi (eds), The African Union and its Institutions (Auckland Park: Fanele, 2008). 
Human Rights Watch (HRW). (2011). They Killed Them Like It Was Nothing: the need for justice for Côte d'Ivoire's post-election crimes', 6 October 2011, <https://www.hrw.org/ report/2011/10/05/theykilled-them-it-was

Isenhart, M. W. \& Spangle, M. (2000). Collaborative Approaches to Resolving Conflict, Thousand Oaks, CA: Sage Publication, 2000, 242.

Khadiagala, G. (2012). The Role of the African Union, New Partnership for Africa's Development, and African Development Bank in Post-Conflict Reconstruction and Peacebuilding', in D. Curtis and G. A. Dzinesa (eds), Peacebuilding, Power and Politics in Africa (Athens, OH: Ohio University Press, 2012).

Kibasomba, R. (2002). Conflict Prevention and Resolution". Paper presented at the Ten Year Presidential Review Conference, 12- 13 November. (Available at: http://www.thepresidency.gov.za/docs/pcsa/irps/kibasomba.pdf.

Klingebiel, S. (2005). 'Africa's new peace and security architecture: converging the roles of external actors and African interests', African Security Review, 14/2 (2005), 35-44.

Kode D. (2016). The Complexities of Democracy building in the Conflict-Affected States: The Role of Ecowas and The African Union in Côte D'ivoire.

Mays, T. M. (2002). Africa's First Peacekeeping Operation: The OAU in Chad 1981-1982 (West Port: Praeger, 2002).

Mogalakwe, M. (2006). Research Report. The Use of Documentary Research Methods in Social Research. African Sociological Review, 10(1), 221-230.

Mwanasali, M. (2008). From Non-interference to Non-indifference: The Emerging Doctrine of Conflict Prevention in Africa', in J. Akokpari, A. Ndinga-Muvumba and R. Murithi (eds), The African Union and its Institutions (Auckland Park: Fanele, 2008).

Peter D. (2016). The wars are ravaging Africa in 2016. The National Interest. The Buzz. www.nationalinterest.org

Shillinger, K. (2009). Africa's Peacemaker: Lessons from South African Conflict Mediation, SAIIA.

Swart, G. \& Solomon, H. (2004). Conflict in the DRC: A Critical Reflection of the Lusaka Ceasefire Agreement. SAIIA Report, 40.

World Bank. (2016). Data for Zimbabwe, Angola, Botswana, Lesotho, Malawi, Mauritius, Mozambique, Namibia, Seychelles, South Africa, Swaziland, Tanzania, Zambia, Congo, Dem. Rep. The World Bank. Available at (http://data.worldbank.org/?locations=ZW-AO-BW-LS-MW-MU-MZ-NA-SC-ZA-SZ-TZ-ZMCD). Accessed 17 August, 2016.

Yound, C. (1991). Self-determination, Territorial Integrity and the African State', in F. M. Deng and I. W. Zartman (eds), Conflict Resolution in Africa (Washington, DC: The Brookings Institute, 1991).

Zartman, W. (2005). Cowardly Lions: Missed Opportunities to Prevent Deadly Conflict and State Collapse (Boulder, CO: Lynne Rienner, 2005).

Zounmenou, D. D. \& Loua, R. S. (2018). Confronting Complex Political Crises in West Africa: An Analysis of ECOWAS Responses to Niger and Côte d'Ivoire', Institute for Security Studies Paper no. 230, December 2011, <https://www.issafrica.org/uploads/Paper230.pdf>, accessed 4 March 2018. 